\title{
Structural Analysis and Total Coal Demand Forecast in China
}

\author{
Qing Zhu, ${ }^{1,2}$ Zhongyu Zhang, ${ }^{1,2}$ Rongyao Li, ${ }^{3}$ Kin Keung Lai, ${ }^{2,4}$ \\ Shouyang Wang, ${ }^{5}$ and Jian Chai ${ }^{2,5}$ \\ ${ }^{1}$ School of Finance and Economics, Xian Jiaotong University, Xian 710061, China \\ ${ }^{2}$ International Business School, Shaanxi Normal University, Xian 710119, China \\ ${ }^{3}$ College of Economics and Management, Southwest University, Chongqing 400715, China \\ ${ }^{4}$ College of Business, City University of Hong Kong, Tat Chee Avenue, Kowloon, Hong Kong \\ ${ }^{5}$ National Center for Mathematics and Interdisciplinary Science, Chinese Academy of Sciences, Beijing 100190, China
}

Correspondence should be addressed to Jian Chai; chaijian0376@126.com

Received 7 March 2014; Accepted 16 May 2014; Published 5 June 2014

Academic Editor: Chuangxia Huang

Copyright (C) 2014 Qing Zhu et al. This is an open access article distributed under the Creative Commons Attribution License, which permits unrestricted use, distribution, and reproduction in any medium, provided the original work is properly cited.

Considering the speedy growth of industrialization and urbanization in China and the continued rise of coal consumption, this paper identifies factors that have impacted coal consumption in 1985-2011. After extracting the core factors, the Bayesian vector autoregressive forecast model is constructed, with variables that include coal consumption, the gross value of industrial output, and the downstream industry output (cement, crude steel, and thermal power). The impulse response function and variance decomposition are applied to portray the dynamic correlations between coal consumption and economic variables. Then for analyzing structural changes of coal consumption, the exponential smoothing model is also established, based on division of seven sectors. The results show that the structure of coal consumption underwent significant changes during the past 30 years. Consumption of both household sector and transport, storage, and post sectors continues to decline; consumption of wholesale and retail trade and hotels and catering services sectors presents a fluctuating and improving trend; and consumption of industry sector is still high. The gross value of industrial output and the downstream industry output have been promoting coal consumption growth for a long time. In 2015 and 2020, total coal demand is expected to reach 2746.27 and 4041.68 million tons of standard coal in China.

\section{Introduction}

As the basic source of energy, coal has facilitated the rapid development of the Chinese economy and has had a positive effect on the stability of the market economy. Therefore, in order to avoid indiscriminate production effectively, improving the efficiency of the coal industry and ensuring national energy security and accurate prediction of coal demand are necessary.

In the past, scholars have established a variety of energy demand forecasting models for different countries and regions as well as different kinds of energy. Traditional methods such as time series, regression, econometric, decomposition, unit root test and cointegration, ARIMA (autoregressive integrated moving average), and input-output, as well as soft computing techniques such as fuzzy logic, GA (genetic algorithm), and ANN (artificial neural networks) are being extensively used for demand side management. Support vector regression, ACO (ant colony), and PSO (particle swarm optimization) are new techniques being adopted for energy demand forecasting. Bottom up models such as MARKAL (acronym for MARKet ALlocation) and LEAP (long-range energy alternatives planning model) are also being used at the national and regional level for energy demand management [1].

For foreign energy consumption, Ediger and Akar [2] considered that estimated economic and demographic parameters usually deviate from the realizations. Time-series forecasting appears to give better results, so they used the ARIMA and SARIMA (seasonal ARIMA) methods to estimate the future primary energy demand of Turkey from 2005 to 2020. Mohr and Evans [3] considered the model of worldwide coal production developed for three scenarios (Hubbert Linearisation method scenario, reserves plus 
cumulative production scenario, best guess scenario). The ultimately recoverable resources (URR) estimates used in the scenarios ranged from $700 \mathrm{Gt}$ to $1243 \mathrm{Gt}$. Unler [4] proposed a model to forecast the energy demand of Turkey until 2025 by using PSO-based energy demand forecasting (PSOEDF) and made a comparison with the ant colony optimization (ACO) energy demand estimation model. The result showed that the former algorithm had better accuracy. Lee and Chiu [5] applied a newly developed panel smooth transition regression model with the error-correction term (PSECM) to estimate the nonlinear relationships among energy consumption, real income, and real energy prices for 24 OECD countries.

For domestic energy consumption, various approaches to forecasting have been used in the literature, including cointegration and error correction models [6] and demand equations [7]. In 2002, $\mathrm{Yu}$ and $\mathrm{Zhu}$ [8] proposed an improved hybrid algorithm called PSO-GA (particle swarm optimization-genetic algorithm) for energy demand forecasting in China with higher precision compared with single optimization methods, such as GA, PSO or ant colony optimization, and multiple linear regressions. Results of this study show that China's energy demand will be 4.70 billion tons coal equivalent in 2015. In the same year, they also proposed mixencoding particle swarm optimization and radial basis function (MPSO-RBF) network-based model to forecast China's energy consumption until 2020, based on GDP, population, proportion of industry in GDP, urbanization rate, and share of coal energy for the period from 1980 to 2009 [9]. Zhang et al. [10] forecast transport energy demand for 2010, 2015, and 2020 based on partial least square regression (PLSR) method under two scenarios by analyzing gross domestic product (GDP), urbanization rate, passenger-turnover, and freight-turnover for the period of 1990-2006. Crompton and $\mathrm{Wu}$ [11] applied the Bayesian vector autoregressive methodology to forecast China's energy consumption and to discuss potential implications. The results of this paper suggested that total energy consumption should increase to $2173 \mathrm{MtCE}$ in 2010 , an annual growth rate of $3.8 \%$, which is slightly slower than the average rate in the past decade due to structural changes in the Chinese economy.

Among them, some of the latest techniques such as Bayesian vector autoregression (BVAR), support vector regression, ant colony, and particle swarm optimization models are being used in energy demand analysis. Chai et al. [12] established a VARX (vector autoregressive model with exogenous variables) model of crude oil market structure to study the effect of every variable on oil price by screening variables with price, supply, demand of oil, dollar index and China oil net import as the endogenous variables and reserve, speculative factors as the exogenous variables. Then, based on this VARX model and the Bayes theory, a MSBVAR (Markov switching bayes vector autoregression) model is established to identify and analyze the structural changing of oil price system structure within the study period. BVAR model and Granger-causality are applied to study growth in energy demand and the relationship between energy consumption and real gross domestic product per capita in selected few Caribbean countries [13]. Bayesian neural network approach is used for short term electric load forecasting [14, 15].
The BVAR model can avoid the rigid inclusion/exclusion restrictions of VAR models by allowing inclusion of many coefficients while simultaneously controlling the extent of mathematical expectation and standard deviation to which they can be influenced by the data. This reduces the spurious correlations captured by the model, thereby reducing forecast error and improving forecasting performance.

On the basis of the background and demand mentioned above, this paper attempts to analyze structural changes of coal consumption during the past 30 years and forecast future coal demand in China up to 2020. This paper includes seven parts: introduction, describing the realistic background and the academic background for research topic; variables selection and data processing, screening the core effect factors for total coal demand; methodology, introducing VAR, BVAR, and ETS models; forecast of total coal consumption, based on VAR models, applying the impulse response function and variance decomposition to portray the dynamic correlations between coal consumption and economic variables, and forecasting total coal consumption by BVAR models; structural analysis of total coal consumption, establishing ETS models based on coal consumption of seven sectors to analyze structural changes of coal consumption and forecast total coal consumption; results and discussion, comparing forecast results of total coal consumption by BVAR models and ETS models; conclusions.

\section{Variables Selection and Data Processing}

Many factors that affect future demand for coal, such as domestic and international price of coal, the national policy of saving energy and reducing consumption, efficiency of resource utilization, coal consumption of downstream industries, railway and highway capacity for coal transportation, technology development, urbanization, industrial growth, industrial structure, the supply and price of other alternative energy sources (such as oil, natural gas, hydropower, nuclear power, etc.), coal production cost (pollution control costs, coal mine safety production costs, exit cost, etc.), and consumer habits.

Based upon the China Statistical Yearbook, China Energy Statistical Yearbook, China Coal Industry Yearbook, and WIND Database, this paper has identified the following influence factors of coal demand from 1985 to 2011: (1) unit of coal consumption is ten thousand tons of standard coal; (2) since most coal is consumed in industry and contribution of the secondary industry to gross domestic product (GDP) fluctuates sharply, gross industrial output (100 million yuan) and industrial structure (\%) are considered important factors that affect coal consumption; (3) electric power, steel, building materials, and chemical industry are four major downstream industries that consume coal, so output of thermal power (100 million kilowatt hour), crude steel (10000 tons), and cement (10000 tons) are also factors used to forecast coal consumption; (4) effect of international prices and supply position of different substitute sources of energy on domestic coal usage and consumption, such as coal price (Newcastle in Australia/Ken blah FOB), oil price 
(Europe Brent Spot Price FOB), natural gas price (Louisiana spot prices), and producer price indices for domestic industrial products by sector (power, coal, and petroleum); (5) per capita GDP (yuan) and urbanization rate (\%) data are collected since the improvement of consumer capacity and change of urban structure affect the energy consumption per capita in China.

First of all, in order to eliminate the heteroscedasticity of the economic time series data and to linearize its trend, the above variables are put into the natural logarithms. Then, to prevent false regression leading to an invalid conclusion, ADF (Augment Dikey-Fuller) unit root test and cointegration test are used to examine stationarity and long-run equilibrium relationship of logarithmic time series, respectively. Finally, only the following 5 groups' data meet the conditions of the VAR model: coal consumption (COAL), gross value of industrial output (IND), output of cement industrial products (CEM), output of crude steel industrial products (STE), and output of thermal power industrial products (POW).

\section{Methodology}

3.1. VAR. A vector autoregressive (VAR) model based on statistical properties of the data is established, without exerting a theory of a priori constraints for the data mechanism, so it is an unstructured time series model, not a structural econometric model with a theoretical foundation. Specifically, all economic variables are considered as endogenous variables in VAR model, through multistage lag regression, to estimate their relationships and for establishing forecast models.

In 1980, Sims [16] introduced the VAR model and promoted its application for dynamic analysis of the economic system extensively. VAR model is used to forecast interconnected time series system and analyze dynamic shocks from stochastic disturbances to variables, so as to explain the influence of various economic shocks on economic variables.

An unrestricted vector autoregression (UVAR) model containing $n$ time series variables and a lag length of $p$ has the following general form:

$$
\begin{aligned}
& y_{t}=c+A_{1} y_{t-1}+\cdots+A_{p} y_{t-p}+\mu_{t}, \\
& \mu_{t} \sim \text { i.i.d.N }\left(0, \sigma^{2}\right), \quad t=1,2, \ldots, n,
\end{aligned}
$$

where $y_{t}=\left(y_{1}, y_{2}, \ldots, y_{n}\right)^{\prime}$ is an $(n \times 1)$ vector of endogenous variables; $c$ is an $(n \times 1)$ vector of intercept terms; $A_{i}, i>1$, are $(n \times n)$ coefficient matrices; and $\mu_{t}$ is an $(n \times 1)$ vector of the independent normal random error vector.

Based on the VAR model, the dynamic relationship between the variables can be analyzed by impulse response function and variance decomposition.

Impulse response function describes the effect on the current and future variables from information shocks of a random disturbance which equals a standard deviation, and vividly depicts the path changes of the dynamic interaction between the variables and tests the intensity and duration of the impact of economic variables on coal consumption. This function implies that decomposition does not have to completely depend on the order of the variables in the VAR system, so as to improve the stability and reliability of the estimation results.

Variance decomposition method decomposes mean square error (MSE) of the forecast system into contributions of each variable, facilitating examination of MSE decomposition of any endogenous variables and measurement of the relative importance of random disturbances for the variables by comparing the variance contribution rate. In this paper, through the variance decomposition method, the role of the economic variables fluctuation in coal consumption growth can be determined.

3.2. $B V A R$. In (1), the vector $c$ contains $n$ intercept terms and each matrix $A_{i}$ contains $n^{2}$ coefficients; hence, with the increase of variables and lag, $n+p n^{2}$ coefficients must be estimated, which increase exponentially with the number of variables in the system. A major problem in estimation of VAR models when $p$ is large is over-parameterization, where too many coefficients must be estimated, relative to sample size. This can lead to an overfitting problem: the large number of coefficients in unrestricted VAR models tends to fit the data unrealistically well, while performing poorly in out-of-sample forecasting due to the effects of spurious correlations in the data set. Over-fitting of the data can distort the long-run relationships between variables in the model and inflate coefficient values on distant lags due to low degrees of freedom [17]. In addition, VAR model ignores the a priori information and presets the same importance for all estimated parameters, which can lead to the wrong model. There are many ways to overcome the over-fitting problem. By applying certain constraints on the parameters, such as reducing the lag length, or removing some of the variables in an individual equation, can solve the problem of lower degrees of freedom effectively. But from the view of Bayesian, this means that forecasters believe that the probability of removing lags whose coefficient is zero is $100 \%$. But it is impossible to know whether this constraint is established.

An alternate approach is the BVAR method proposed by Litterman [18, 19], Doan et al. [20], Sims [21], and Sims and Zha [22]. The BVAR approach modifies the OLS estimates of (1) by treating all coefficients as random variables around their Bayesian prior mean, such that the model has the flexibility to impose these priors, to varying degrees, on the coefficient estimates.

3.3. ETS. ETS technology appeared and was used in the 1950s. After decades of development, it became mature. However, selection of "optimum" model from different models for use began few years ago. Hyndman and Khandakar [23] summed up exponential smoothing models and divided them into fifteen types. For more details, see Table 1.

Error, Trend, and Seasonal of ETS model, respectively, represent error term, trend term, and season term, in which, (Trend, Seasonal) group includes fifteen models listed in Table 1. Residual error term is classified as overlapping forms (addition forms) and multiplication forms. On the assumption of $y_{t}=\mu_{t}+\varepsilon_{t}$, it is an additive errors model. On the assumption of $y_{t}=\mu_{t}\left(1+\varepsilon_{t}\right)$, it is a multiplication errors model. Under the circumstances of consideration of different 
TABLE 1: Classification and summary of ETS models.

\begin{tabular}{lccc}
\hline \multirow{2}{*}{ Trend component } & \multicolumn{3}{c}{ Seasonal component } \\
& $\mathrm{N}$ (none) & A (additive) & $\mathrm{M}$ (multiplicative) \\
\hline $\mathrm{N}$ (none) & $\mathrm{N}, \mathrm{N}$ & $\mathrm{N}, \mathrm{A}$ & $\mathrm{N}, \mathrm{M}$ \\
$\mathrm{A}$ (additive) & $\mathrm{A}, \mathrm{N}$ & $\mathrm{A}, \mathrm{A}$ & $\mathrm{A}, \mathrm{M}$ \\
$\mathrm{A}_{\mathrm{d}}$ (additive damped) & $\mathrm{A}_{\mathrm{d}}, \mathrm{N}$ & $\mathrm{A}_{\mathrm{d}}, \mathrm{A}$ & $\mathrm{A}_{\mathrm{d}}, \mathrm{M}$ \\
$\mathrm{M}$ (multiplicative) & $\mathrm{M}, \mathrm{N}$ & $\mathrm{M}, \mathrm{A}$ & $\mathrm{M}, \mathrm{M}$ \\
$\begin{array}{l}\mathrm{M}_{\mathrm{d}} \text { (multiplicative } \\
\text { damped) }\end{array}$ & $\mathrm{M}_{\mathrm{d}}, \mathrm{N}$ & $\mathrm{M}_{\mathrm{d}}, \mathrm{A}$ & $\mathrm{M}_{\mathrm{d}}, \mathrm{M}$ \\
\hline
\end{tabular}

error forms, the above fifteen models can be extended to thirty types. From the forecast results alone, addition form or multiplication form hardly influence residual error term. However, for different sampled data, various residual error forms seem superior or inferior. Because dividing by 0 is involved, attention should be paid to select different addition or multiplication forms for residual error, trend term, or season term. When samples are all positive values, using residual error multiplication form presents an advantage. However, when samples are zero value or negative value, multiplication form model is not applicable.

\section{Forecast of Total Coal Consumption by BVAR Models}

In order to analyze the dynamic relationship between coal consumption and economic variables, $5 \mathrm{~d}$ VAR model is built based on (1). According to the lag length criteria (likelihood ratio, final prediction error, AIC, SC, and Hannan-Quinn information criterion), VAR (2) is the most appropriate model. VAR models are set up as follows:

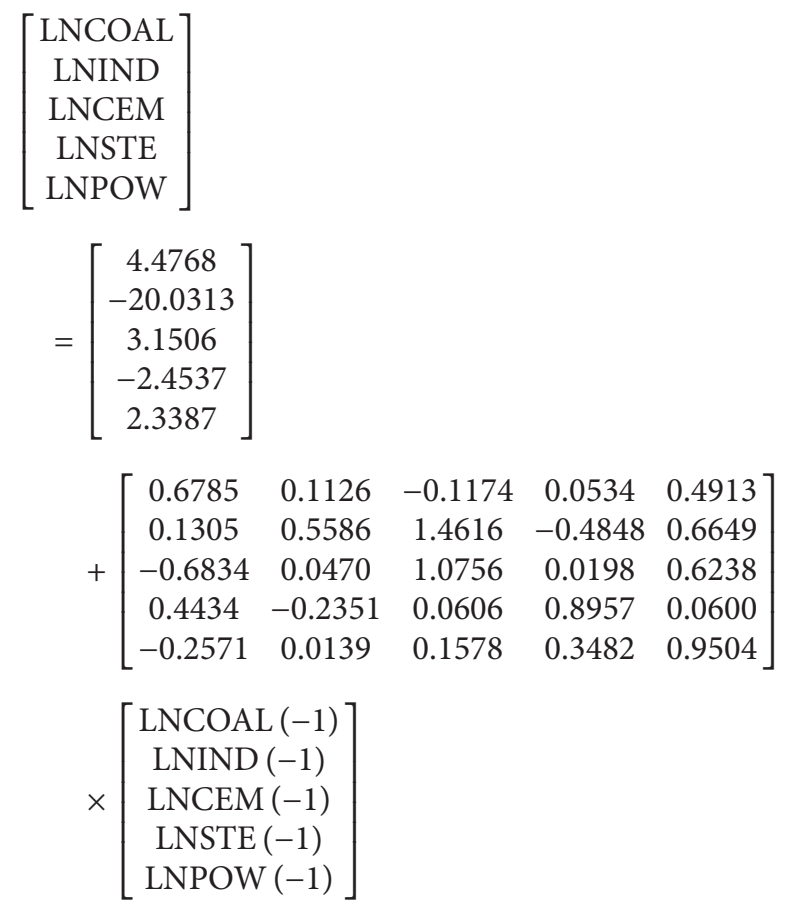

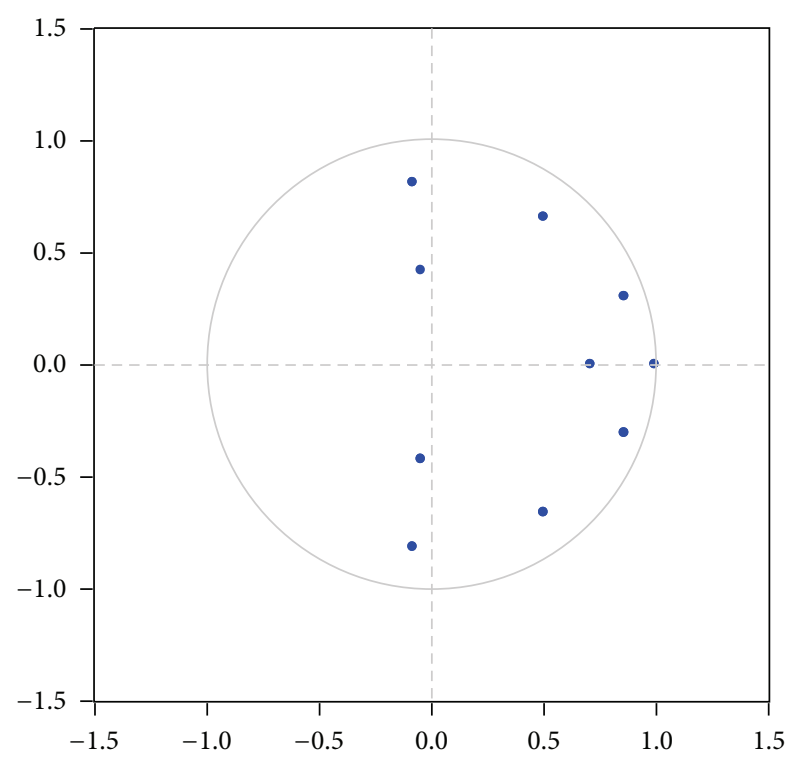

FIGURE 1: Inverse roots of AR characteristic polynomial.

$$
\begin{aligned}
& +\left[\begin{array}{ccccc}
-0.3453 & -0.1248 & -0.0067 & 0.1699 & -0.2082 \\
2.0973 & -0.4018 & -0.3793 & -0.5128 & -0.4853 \\
0.3309 & -0.0134 & -0.7911 & -0.0454 & 0.3111 \\
-0.2974 & 0.0022 & -0.0554 & -0.2683 & 0.7020 \\
-0.0600 & -0.0030 & -0.1852 & -0.1937 & 0.0594
\end{array}\right] \\
& \times\left[\begin{array}{c}
\operatorname{LNCOAL}(-2) \\
\operatorname{LNIND}(-2) \\
\operatorname{LNCEM}(-2) \\
\operatorname{LNSTE}(-2) \\
\operatorname{LNPOW}(-2)
\end{array}\right]+\left[\begin{array}{l}
\varepsilon_{1} \\
\varepsilon_{2} \\
\varepsilon_{3} \\
\varepsilon_{4} \\
\varepsilon_{5}
\end{array}\right] .
\end{aligned}
$$

The $R$-squared of the models are 0.9981, 0.9951, 0.9966, and 0.9986 , which indicate good simulation results. At the same time, the reciprocals of all roots locate inside the unit circle when calculating the AR characteristic polynomial (Figure 1), which shows that the established VAR (2) model is stable. That is to say, when a variable changes in the model (i.e., to generate a shock), it leads to changes in other variables too. But as time goes on, the effect gradually disappears. In Figure 1, the horizontal axis represents the real number axis; the vertical axis represents the imaginary numbers axis; the unit circle is a circle of radius 1 and center at the origin; the points in the unit circle represent roots of the characteristic equation on VAR (2) model.

Based on the VAR model, the dynamic relationship between the variables can be analyzed by impulse response function and variance decomposition.

In Figure 2, the horizontal axis represents the lag periods of shock from innovation (unit: years); the vertical axis represents the response degree from the dependent variables to the explaining variables; the solid line is the calculated value of the impulse response function. The lag period is set to 15 years. 


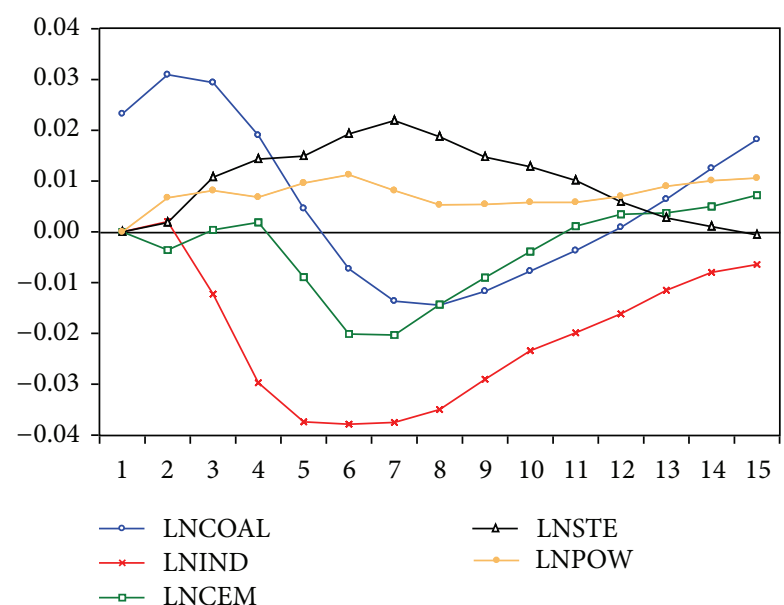

Figure 2: Responses of LNCOAL to LNCOAL, LNIND, LNCEM, LNSTE, and LNPOW.

According to Figure 2, the line graph shows that when the explaining variables (coal consumption, gross value of industrial output, cement output, crude steel industrial output, and thermal power output) are shocked from innovation, respectively, how does the dependent variable (coal consumption) respond during the future 15 periods. That is to say, when these five factors change, respectively, we can forecast how much and how long will coal consumption respond.

Firstly, coal consumption volatility responds strongly to its own shock which is shown by the blue line, and in the first 15 periods it shows a fluctuating trend. Early, as a strong positive response, in the second period, it reaches the peak at $0.0310 \%$ and then plunges to the lowest point at $-0.0145 \%$ in the eighth period. From this point onwards, the period between 9 and 15 experiences a gradual growth until the numbers become positive response again. This shows that coal consumption and its lagging values have a strong correlation. Secondly, after suffering a positive shock, gross value of industrial output only brings positive response to coal consumption in the second period, and then it quickly drops to a negative response, to the lowest point of $-0.0379 \%$ in the sixth period. Afterwards, it rises to zero slightly. This indicates that the increase of the gross value of industrial output immediately leads to an increase in coal consumption, but in the long term it reduces consumption. The reasons may be that more output provides more capital for internal restructuring and technological progress, thus reducing coal consumption costs and increasing profits. Thirdly, coal consumption volatility responds modestly to cement output shocks in the early stage. From the fifth period to the eleventh period, the response shows a large fluctuation from negative to positive. Fourthly, coal consumption volatility has increasing positive response to crude steel industrial output shocks gradually over time, and in the seventh period that reaches the peak of $0.0219 \%$. Fifthly, a positive shock on thermal power output brings positive response to coal consumption, which has weak intensity and stable tendency. These results indicate that the development of downstream

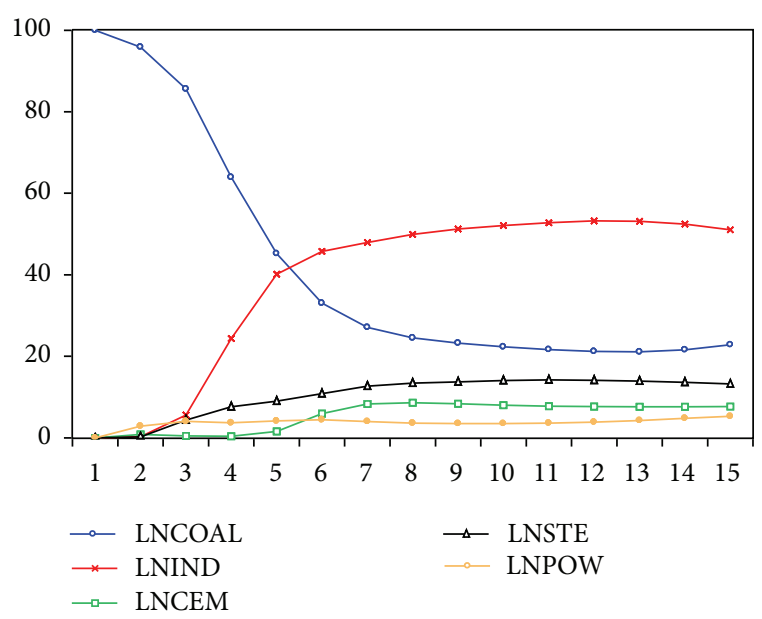

FIGURE 3: Factors variance decomposition on the effect of LNCOAL.

industries drives an increase in demand for coal, whose longterm relation is in the same direction.

In Figure 3, the horizontal axis represents the lag periods of impact from innovation (unit: years); the vertical axis represents the contribution rate to coal consumption from the economic variables.

As shown in Figure 3, in the future 15 periods, coal consumption has the greatest impact during the first five periods with its own contribution rate above $40 \%$. Since then, rates in the rest of the period level off at about $22 \%$. The contribution rate of the gross value of industrial output to coal consumption increases steeply from the third period and then exceeds all other variables at the sixth period and remains stable and high between 51 and 53\%. Thermal power industry had the highest contribution in the second period, but after that its contribution rates decline to $3-4 \%$. Contribution rates of crude steel industry have obvious rise from the third period and make the largest contribution in the downstream industries between $12-14 \%$. The contribution rate of cement industry has an obvious rise in the sixth period, after that, the contribution rate remains in the $7-8 \%$ level. Therefore, in the long run, industrial output has the biggest contribution to the changes of coal consumption; in a short time, coal consumption have the biggest contribution to own changes.

The system of priors commonly used in the specification of BVAR models includes conjugate prior distribution, maximum entropy prior distribution, ML-II prior distribution, and multilayer prior distribution. Different BVAR prior distributions have different impacts on the prediction results. This paper uses the $R$ software to forecast coal consumption based on three kinds of prior distribution in the MSBVAR package. Command is run as follows: $\mathrm{R}>$ fcast $<-$ szbvar (coal, $p=2$, lambda $0=0.6$, lambda $1=0.1$, lambda $3=2$, lambda $4=0.25$, lambda $5=0$, mu $5=0$, mu $6=0$, prior $=0$ ). There are three different prior distributions: $0=$ Normal-Wishart prior, 1 = Normal-flat prior, and 2 = flat-flat prior (i.e., akin to MLE). The forecasting results from 2012 to 2020 are shown in Table 4. 


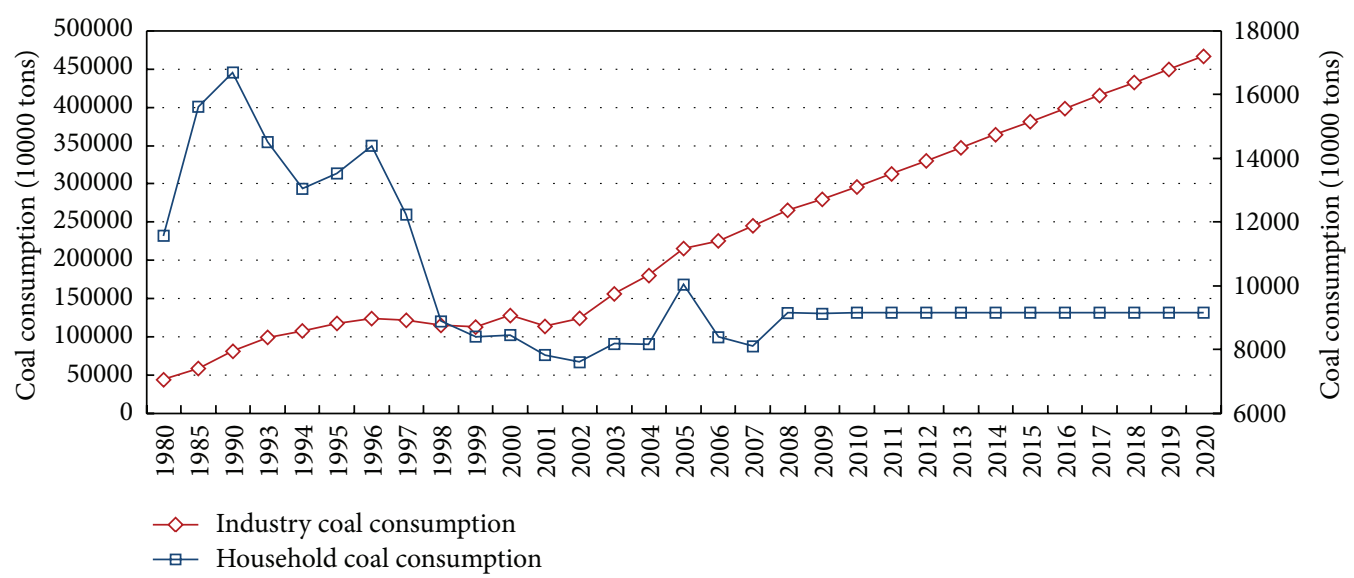

FIGURE 4: Changes of industry and household coal consumption.

\section{Structural Analysis of Total Coal Consumption}

A univariate ETS (exponential smoothing) forecast model is used to predict coal consumption of each sector in 2020 in the forecast package for $R$. Error, Trend, and Seasonal of ETS model denote error term $(A, M, Z)$, trend term $(N, A, M, Z)$, and season term $(\mathrm{N}, \mathrm{A}, \mathrm{M}, \mathrm{Z})$, respectively, in which the group includes thirty models.

From the coal balance sheet in China Statistical Yearbook and WIND Database, coal consumption data of seven sectors are selected for the period 1980-2010. The balance equation for coal consumption: Total coal consumption (TO) = Agriculture, Forestry, Animal Husbandry, Fishery and Water Conservancy (AFAFW) + Industry (IND) + Construction $(\mathrm{CON})+$ Transport, Storage and Post $(\mathrm{TSP})+$ Wholesale and Retail Trades, Hotels and Catering Services (WRHC) + Other Sectors (OS) + Household Consumption (HC). Unit is 10000 tons.

The final models (Table 2) are selected from thirty models by comparing information criterion (AIC, BIC, AICc) and forecast precision (mean error, root mean square error, mean absolute error, maximum permissible errors, mean absolute percentage error, mean absolute error square) (Table 3). Command is run as follows: $\mathrm{R}>$ fcast $<$-forecast(est(x)).

As can be seen from the Table 4, the total coal consumption is the sum of coal consumption in seven sectors, which is 3.9728663 billion tons in 2015. This value is similar to the goal in the development of coal industry in the twelfth five-year plan which is 3.9 billion tons in 2015. By 2020, China's total coal consumption will reach 4.83 billion tons with an annual growth rate of $4.36 \%$, of which industry and household consumption account for the largest proportion. In Figure 4, the industry coal consumption was 438 million tons, 811 million tons, 1.278 billion tons, and 2.96 billion tons in 1980, 1990, 2000, and 2010, respectively, and it is predicted to reach 4.669 billion tons in 2020 accounting for $96.67 \%$ of total coal consumption. Therefore, to reduce coal consumption in China, industrial energy conservation and emissions reduction are the fastest and most effective breakthrough points, including the adjustment of industrial structure and optimization of technology.

However, as the second largest main channel, the proportion of household consumption is decreasing year by year. Figure 4 shows that household consumption was up to 167 million tons in 1990, which accounts for $15.83 \%$ of the total coal consumption. By 2020, household consumption will be 0.92 million tons accounting for $1.89 \%$ of the total coal consumption. In the field of household energy consumption, as the diversity of the type of energy and development of technology, electricity and heating oil are more available and convenient than coal for residents, so less and less coal is used in the household rapidly. This is beneficial to environmental protection and nonrenewable resources saving.

As shown in Figure 5, transport, storage, and post sectors were the largest coal consumption sectors in 1980, but they became the lowest coal consumption sectors after thirty years in 2010, and their coal consumption will decline constantly during the next decade by predictions. The main reason is that coal-fired steam locomotive engines have been replaced by internal combustion and electric locomotives by the railways. So, most of the raw coal has been replaced by fuel and electricity at the same time. Nowadays, road transportation mainly consumes gasoline and diesel oil; waterways transportation mainly consumes fuel oil and diesel oil; air transport mainly consumes aviation kerosene. Therefore, although the development of transport, storage, and post sectors still consumes large amounts of energy, the usage of coal is insignificant.

As the pillar industry of national economy in our country, construction sector is also an energy-intensive industry. Coal consumption increased from 5.56 to 7.1892 million tons between 1980 and 2010, representing a relatively small growth. By forecasting, the amount of coal consumption is still increasing in the future (Figure 5). At the same time, the construction sector does not have a high proportion of coal consumption and accounted for only $0.23 \%$ in 2010 . That is because there are various types of energies consumed by the construction industry, including raw coal, gasoline, diesel oil, fuel oil, heat, electricity, and other petroleum products. With 


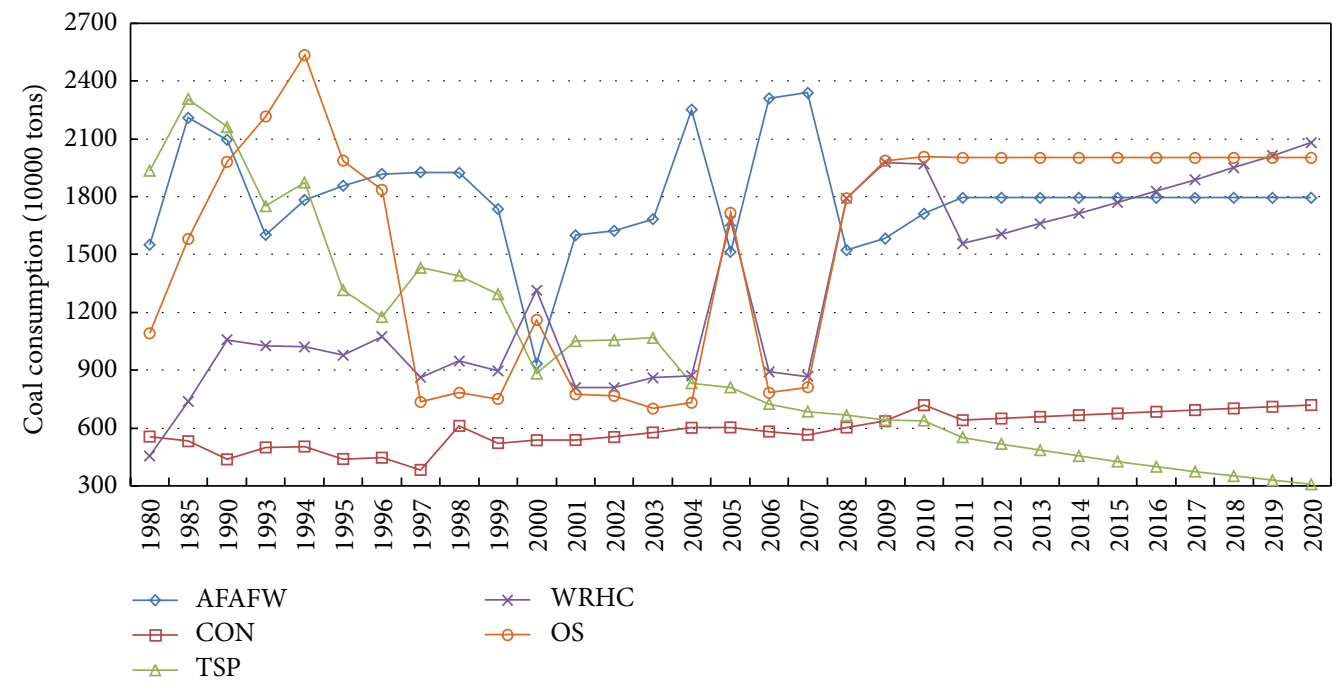

FIGURE 5: Changes of other sectors' coal consumption.

TABLE 2: Formulae for recursive calculations, point forecasts, and parametric estimated value on sector by ETS method.

\begin{tabular}{|c|c|c|}
\hline Variables & Forms & Models and parameters \\
\hline AFAFW & $(\mathrm{M}, \mathrm{N}, \mathrm{N})$ & $\begin{array}{l}l_{t}=\alpha y_{t}+(1-\alpha) l_{t-1}, \hat{y}_{t+h \mid t}=l_{t} \\
y_{t+1}=\hat{y}_{t+1 \mid t}\left(1+\varepsilon_{t}\right), \varepsilon_{t} \sim \operatorname{NID}\left(0, \sigma^{2}\right), 0<\alpha<1,0<\beta<\alpha \\
\alpha=0.0001, l=1793.7859, \sigma=0.1809\end{array}$ \\
\hline IND & $(\mathrm{A}, \mathrm{A}, \mathrm{N})$ & $\begin{array}{l}l_{t}=\alpha y_{t}+(1-\alpha)\left(l_{t-1}+b_{t-1}\right), b_{t}=\beta\left(l_{t}-l_{t-1}\right)+(1-\beta) b_{t-1}, \hat{y}_{t+h \mid t}=l_{t}+h b_{t} \\
y_{t+1}=\hat{y}_{t+1 \mid t}+\varepsilon_{t}, \varepsilon_{t} \sim N I D\left(0, \sigma^{2}\right), 0<\alpha<1,0<\beta<\alpha, \\
\alpha=0.9999, \beta=0.2697, \\
l=54782.1109, b=9338.5498, \sigma=12910.3600\end{array}$ \\
\hline CON & $(\mathrm{A}, \mathrm{A}, \mathrm{N})$ & $\begin{array}{l}l_{t}=\alpha y_{t}+(1-\alpha)\left(l_{t-1}+b_{t-1}\right), b_{t}=\beta\left(l_{t}-l_{t-1}\right)+(1-\beta) b_{t-1}, \hat{y}_{t+h \mid t}=l_{t}+h b_{t} \\
y_{t+1}=\hat{y}_{t+1 \mid t}+\varepsilon_{t}, \varepsilon_{t} \sim N I D\left(0, \sigma^{2}\right), 0<\alpha<1,0<\beta<\alpha \\
\alpha=0.0009, \beta=0.0009, l=448.3868, b=8.7382, \sigma=53.6530\end{array}$ \\
\hline TSP & $(\mathrm{M}, \mathrm{M}, \mathrm{N})$ & $\begin{array}{l}l_{t}=a y_{t}+(1-a) l_{t-1} b_{t-1}, b_{t}=\beta\left(l_{t} / l_{t-1}\right)+(1-\beta) b_{t-1}, \hat{y}_{t+h \mid t}=l_{t} b_{t}^{h} \\
y_{t+1}=\hat{y}_{t+1 \mid t}\left(1+\varepsilon_{t}\right), \varepsilon_{t} \sim \operatorname{NID}\left(0, \sigma^{2}\right), 0<\alpha<1,0<\beta<\alpha \\
\alpha=0.0001, \beta=0.0001, l=2305.0531, b=0.9371, \sigma=0.1049\end{array}$ \\
\hline WRHC & $(\mathrm{M}, \mathrm{M}, \mathrm{N})$ & $\begin{array}{l}l_{t}=a y_{t}+(1-a) l_{t-1} b_{t-1}, b_{t}=\beta\left(l_{t} / l_{t-1}\right)+(1-\beta) b_{t-1}, \hat{y}_{t+h \mid t}=l_{t} b_{t}^{h} \\
y_{t+1}=\hat{y}_{t+1 \mid t}\left(1+\varepsilon_{t}\right), \varepsilon_{t} \sim \operatorname{NID}\left(0, \sigma^{2}\right), 0<\alpha<1,0<\beta<\alpha \\
\alpha=0.0001, \beta=0.0001, l=765.1436, b=1.0328, \sigma=0.2562\end{array}$ \\
\hline OS & $(\mathrm{A}, \mathrm{N}, \mathrm{N})$ & $\begin{array}{l}l_{t}=a y_{t}+(1-a) l_{t-1}, \hat{y}_{t+h \mid t}=l_{t} \\
y_{t+1}=\hat{y}_{t+1 \mid t}+\varepsilon_{t}, \varepsilon_{t} \sim \operatorname{NID}\left(0, \sigma^{2}\right), 0<\alpha<1,0<\beta<\alpha \\
\alpha=0.8917, l=1148.7978, \sigma=497.8256\end{array}$ \\
\hline $\mathrm{HC}$ & $(\mathrm{M}, \mathrm{N}, \mathrm{N})$ & $\begin{array}{l}l_{t}=a y_{t}+(1-a) l_{t-1}, \hat{y}_{t+h \mid t}=l_{t} \\
y_{t+1}=\hat{y}_{t+1 \mid t}\left(1+\varepsilon_{t}\right), \varepsilon_{t} \sim \operatorname{NID}\left(0, \sigma^{2}\right), 0<\alpha<1,0<\beta<\alpha \\
\alpha=0.9999, l=11373.6307, \sigma=0.1327\end{array}$ \\
\hline TO & $(\mathrm{A}, \mathrm{A}, \mathrm{N})$ & $\begin{array}{l}l_{t}=\alpha y_{t}+(1-\alpha)\left(l_{t-1}+b_{t-1}\right), b_{t}=\beta\left(l_{t}-l_{t-1}\right)+(1-\beta) b_{t-1}, \hat{y}_{t+h \mid t}=l_{t}+h b_{t} \\
y_{t+1}=\hat{y}_{t+1 \mid t}+\varepsilon_{t}, \varepsilon_{t} \sim N I D\left(0, \sigma^{2}\right), 0<\alpha<1,0<\beta<\alpha, \\
\alpha=0.9999, \beta=0.1665, l=78421.9911, b=9365.1674, \sigma=14646.2100\end{array}$ \\
\hline
\end{tabular}

In the above formulae for recursive calculations and point forecasts: $l_{t}$ denotes the series level at time $t ; b_{t}$ denotes the slope at time $t ; \alpha$ and $\beta$ are smoothness index; $h$ denotes the lag period.

the development of technology, the construction sector will become dependent on power and all kinds of oil products increasingly instead of coal, which can improve the energy efficiency and control environmental pollution gradually.

Wholesale and retail trade and hotels and catering services consume coal, electricity, heat, gasoline, diesel oil, liquefied petroleum gas, natural gas, and other varieties of energy.
Influenced by price changes and economic development, this sector has gone through booms and busts repeatedly. From 1980 to 1990 , the sector had a rising trend due to adapting to the market demand quickly; from 1990 to 1997 with high price, the sector was in the integration stage; from 1997 to 1999 , the sector was in a low price and low growth stage; from 2000 to 2004, the sector was in a low price and high 
TABLE 3: Accuracy of forecast models on sector by ETS method.

\begin{tabular}{lcccccccc}
\hline & AFAFW & IND & CON & TSP & WRHC & OS & HC \\
\hline AIC & 310.7869 & 469.4980 & 239.2015 & 272.4609 & 308.5274 & 328.7655 & 371.5486 & 474.7963 \\
AICc & 311.4536 & 471.9980 & 241.7015 & 274.9609 & 311.0274 & 329.4321 & 372.2153 & 477.2963 \\
BIC & 312.8760 & 473.6761 & 243.3796 & 276.6390 & 312.7055 & 330.8545 & 373.6377 & 478.9744 \\
ME & -0.1636 & 1297.1479 & 0.2783 & 5.3547 & -21.8557 & 45.5007 & -105.4612 & 1903.6901 \\
RMSE & 324.4691 & 12910.3640 & 53.6530 & 154.4569 & 309.8943 & 497.8256 & 1540.4774 & 14646.2092 \\
MAE & 255.6755 & 10635.7804 & 39.6210 & 115.8266 & 272.7594 & 365.0402 & 1081.5817 & 11811.2234 \\
MPE & -4.0490 & -0.2898 & -1.0556 & -0.8693 & -10.5543 & -6.4377 & -1.9142 & -0.1609 \\
MAPE & 15.7232 & 9.8982 & 7.7865 & 8.7576 & 27.1766 & 30.0246 & 9.6963 & 9.3149 \\
MASE & 0.7907 & 0.7024 & 0.8702 & 0.7315 & 1.1268 & 0.9915 & 0.9609 & 0.7435 \\
\hline
\end{tabular}

TABLE 4: Forecasting result of coal consumption on sector by ETS method.

\begin{tabular}{lcccccccc}
\hline ETS & TO & AFAFW & IND & CON & TSP & WRHC & OS & HC \\
\hline 2011 & 328820.36 & 1793.79 & 313117.60 & 640.68 & 552.60 & 1555.68 & 2000.86 & 9159.17 \\
2012 & 345931.25 & 1793.79 & 330203.50 & 649.42 & 517.87 & 1606.66 & 2000.86 & 9159.17 \\
2013 & 363045.90 & 1793.79 & 347289.30 & 658.16 & 485.32 & 1659.31 & 2000.86 & 9159.17 \\
2014 & 380164.41 & 1793.79 & 364375.20 & 666.91 & 454.81 & 1713.68 & 2000.86 & 9159.17 \\
2015 & 397286.63 & 1793.79 & 381461.10 & 675.65 & 426.23 & 1769.84 & 2000.86 & 9159.17 \\
2016 & 414412.38 & 1793.79 & 398546.90 & 684.39 & 399.44 & 1827.84 & 2000.86 \\
2017 & 431541.82 & 1793.79 & 415632.80 & 693.14 & 374.33 & 1887.74 & 2000.86 \\
2018 & 448674.80 & 1793.79 & 432718.70 & 701.88 & 350.80 & 1949.61 & 2000.86 & 9159.17 \\
2019 & 465811.18 & 1793.79 & 449804.50 & 710.62 & 328.75 & 2013.50 & 2000.86 & 915.17 \\
2020 & 482951.14 & 1793.79 & 466890.40 & 719.37 & 308.09 & 2079.48 & 2000.86 & 9159.17 \\
\hline
\end{tabular}

Unit: 10000 tons.

growth stage; domestic prices began to soar in 2005 and since the American subprime crisis and the domestic policy adjustment in 2008, the sector appears to have had violent fluctuations. However, Figure 5 shows that the wholesale and retail trade, hotels, and catering services will have a growth trend of coal consumption in the future. Industry scale will continue to expand, which is consistent with our country's policy to develop the tertiary industry vigorously.

Agriculture, forestry, animal husbandry, fishery, and water conservancy are the foundation of the national economy. Coal consumption was in the second place before 1990, but in 1993, 2000, 2005, and 2008 there was a great fall (Figure 5); in contrast, coal consumption of wholesale and retail trade, hotels, and catering services, and other sectors had an obvious increase in these three years. Considerable contact with the change of the prices is guessed.

\section{Results and Discussion}

Table 5 shows prediction results of BVAR models under the three different prior distributions and the ETS models. The unit is 10000 tons in ETS models, which is 10000 tons of standard coal in BVAR models. So the results of ETS model are multiplied by the converted coefficient of 0.7143 as tons of standard coal.

The result of BVAR models under the normal-Wishart prior distribution (prior $=0$ ) is the same as under the normalflat prior distribution (prior $=1$ ). Using the ETS model to
TABLE 5: Total coal consumption forecast.

\begin{tabular}{lcccc}
\hline & $\begin{array}{c}\text { BVAR } \\
\text { Prior }=0 \text { or } 1\end{array}$ & $\begin{array}{c}\text { BVAR } \\
\text { Prior }=2\end{array}$ & $\begin{array}{c}\text { ETS } \\
\text { aggregation }\end{array}$ & $\begin{array}{c}\text { ETS } \\
\text { forecast }\end{array}$ \\
\hline 2011 & 238033.37 & 238033.37 & 234876 & 234475 \\
2012 & 252686.75 & 254034.07 & 247099 & 245921 \\
2013 & 268152.68 & 257667.41 & 259324 & 257366 \\
2014 & 284494.14 & 257113.39 & 271551 & 268811 \\
$\mathbf{2 0 1 5}$ & $\mathbf{3 0 1 7 6 2 . 9}$ & $\mathbf{2 7 4 6 2 7 . 2 9}$ & $\mathbf{2 8 3 7 8 2}$ & $\mathbf{2 8 0 2 5 6}$ \\
2016 & 320015.13 & 314720.65 & 296014 & 291701 \\
2017 & 339311.96 & 360700.12 & 308250 & 303146 \\
2018 & 359720.03 & 401190.03 & 320489 & 314591 \\
2019 & 381312.12 & 444913.39 & 332729 & 326037 \\
$\mathbf{2 0 2 0}$ & $\mathbf{4 0 4 1 6 7 . 8 4}$ & $\mathbf{5 0 4 8 2 3 . 6 9}$ & $\mathbf{3 4 4 9 7 2}$ & $\mathbf{3 3 7 4 8 1}$ \\
\hline
\end{tabular}

Unit: 10000 tons of standard coal.

predict coal consumption of every sector and then adding the seven values to get 3.44972 billion tons of standard coal in 2020; only based on the historical total coal consumption, 3.37481 billion tons of standard coal are obtained in 2020 directly. From Table 5, in 2015 forecast results of four methods have small differences. But in 2020, the results of BVAR model are larger than ETS model (Figure 6).

The reason may be that in BVAR model, the gross value of industrial output and the downstream industrial production are influencing factors, whose values are increasing over the 


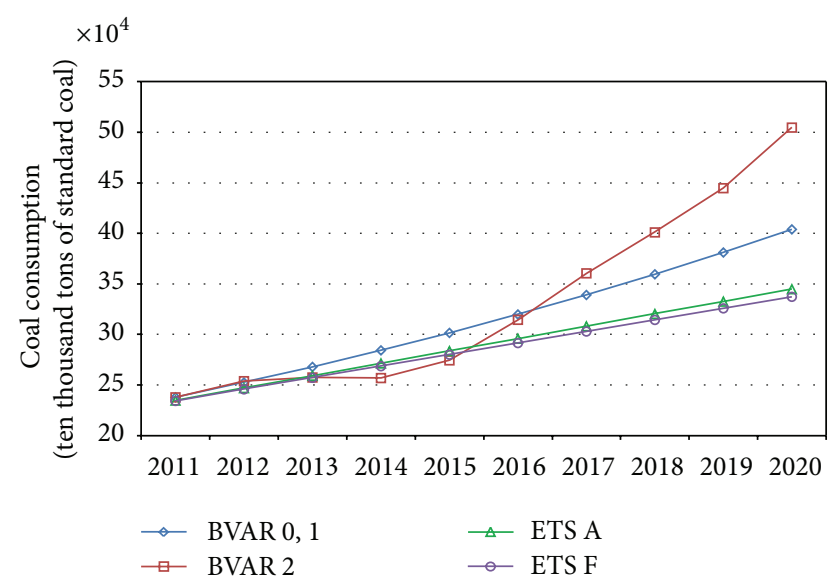

FIGURE 6: Total coal consumption forecast.

years. So they drive the rise in total coal consumption in the long run. However, in ETS model, total coal consumption is the sum of coal consumption in seven sectors, and the above has introduced that the coal consumption of some sectors has showed a decreasing trend, such as agriculture, forestry, animal husbandry, fishery and water conservancy, transport, storage, and post. So the ETS model prediction results are smaller.

\section{Conclusions}

China is a big developing country in the process of industrialization and urbanization, and therefore coal consumption will remain high in the future, for a long time. Based on guaranteeing the stability of the VAR system, coal consumption, gross industrial output value, and the downstream industrial production (crude steel, cement, thermal power) are selected as variables to establish the BVAR (2) model. At the same time, this paper analyses the changes of coal consumption structure based on sector division. The forecast models are selected through comparing information criteria and forecast accuracy comparison from thirty ETS models. By forecasting the total coal consumption and analyzing structural changes, this paper gets the following main conclusions.

(1) Results of the impulse response function indicate that the increased output of the downstream industry will become a driving force of coal consumption. In the first two periods, the same response has been there, with the increase of the gross value of industrial output. Later there will be a negative response.

(2) The variance decomposition results show that the contribution of gross value of industrial output accounted for $50 \%$ of growth in coal consumption and has long-term stable influence; in the downstream industry, the contribution rate of crude steel output is greater than that of the cement output and thermal power output.

(3) In the next decade, from a sector division point of view, industry and household consumption account for the largest proportion of total coal consumption; the proportion of industrial coal consumption will continue to rise, but the proportion of household coal consumption will continue to decline. Transport, storage, and post sectors were the largest consumers of coal consumption in 1980, which will become the lowest in the future. Construction sector, despite its lower reliance on coal, has experienced a rise in coal consumption in recent years. The scales of consumption of wholesale and retail trade, hotels and catering services, agriculture, forestry, animal husbandry, fishery, and water conservancy sectors were influenced by price fluctuations in the past few decades, causing the fluctuation of coal consumption. But in the next decade, coal consumption of both sectors will have a rising trend.

(4) The BVAR (2) forecast models predict that in 2015 coal demand will reach $2.75-3.02$ billion tons of standard coal, and in 2020 it will reach $4.04-5.05$ billion tons of standard coal in China. That is to say, as the momentum of rapid development of China's economy in the future, the coal consumption in 2020 is almost double that of in 2012 which is $2.46-2.53$ billion tons of standard coal. However, because the unrenewable characteristics of the coal and the pollution caused by burning are bound to draw the attention of the country and the residents, how to improve the coal utilization efficiency and promote the use of clean energy will become a main research direction in the future.

\section{Conflict of Interests}

The authors declare that there is no conflict of interests regarding the publication of this paper.

\section{Acknowledgments}

This research is supported by the National Natural Science Foundation of China (no. 71103115); the China Postdoctoral Science Foundation surface of funded projects (no. 2012M510580); the Fundamental Research Funds for the Shaanxi province soft science (no. 2012KRM95). The authors would like to thank the anonymous referees.

\section{References}

[1] L. Suganthi and A. A. Samuel, "Energy models for demand forecasting-a review," Renewable and Sustainable Energy Reviews, vol. 16, no. 2, pp. 1223-1240, 2012.

[2] V. S. Ediger and S. Akar, "ARIMA forecasting of primary energy demand by fuel in Turkey," Energy Policy, vol. 35, no. 3, pp. 17011708, 2007.

[3] S. H. Mohr and G. M. Evans, "Forecasting coal production until 2100," Fuel, vol. 88, no. 11, pp. 2059-2067, 2009.

[4] A. Unler, "Improvement of energy demand forecasts using swarm intelligence: the case of Turkey with projections to 2025," Energy Policy, vol. 36, no. 6, pp. 1937-1944, 2008. 
[5] C.-C. Lee and Y.-B. Chiu, "Modeling OECD energy demand: an international panel smooth transition error-correction model," International Review of Economics \& Finance, vol. 25, pp. 372383, 2013.

[6] H. Chan and S. Lee, "Forecasting the demand for energy in China," Energy Journal, vol. 17, no. 1, pp. 19-30, 1996.

[7] C. V. Hirschhausen and M. Andres, "Long-term electricity demand in China-from quantitative to qualitative growth?" Energy Policy, vol. 28, no. 4, pp. 231-241, 2000.

[8] S.-W. Yu and K.-J. Zhu, "A hybrid procedure for energy demand forecasting in China," Energy, vol. 37, no. 1, pp. 396-404, 2012.

[9] S. W. Yu, Y.-M. Wei, and K. Wang, "China's primary energy demands in 2020: predictions from an MPSO-RBF estimation model," Energy Conversion and Management, vol. 61, pp. 59-66, 2012.

[10] M. Zhang, H. L. Mu, G. Li, and Y. D. Ning, "Forecasting the transport energy demand based on PLSR method in China," Energy, vol. 34, no. 9, pp. 1396-1400, 2009.

[11] P. Crompton and Y. R. Wu, "Energy consumption in China: past trends and future directions," Energy Economics, vol. 27, no. 1, pp. 195-208, 2005.

[12] J. Chai, Z. Y. Zhang, J. L. Fu, J. E. Guo, and S. Y. Wang, "Identification and analysis of the structural mutations in oil price system," Journal of Management Sciences, vol. 27, no. 2, pp. 133-144, 2014 (Chinese).

[13] B. M. Francis, L. Moseley, and S. O. Iyare, "Energy consumption and projected growth in selected Caribbean countries," Energy Economics, vol. 29, no. 6, pp. 1224-1232, 2007.

[14] L. M. Saini, "Peak load forecasting using Bayesian regularization, Resilient and adaptive backpropagation learning based artificial neural networks," Electric Power Systems Research, vol. 78, no. 7, pp. 1302-1310, 2008.

[15] P. Lauret, E. Fock, R. N. Randrianarivony, and J.-F. ManicomRamsamy, "Bayesian neural network approach to short time load forecasting," Energy Conversion and Management, vol. 49, no. 5, pp. 1156-1166, 2008.

[16] C. A. Sims, "Macroeconomics and reality," Econometrica, vol. 48, no. 1, pp. 1-48, 1980.

[17] T. Zha, "A dynamic multivariate model for use in formulating policy," Economic Review, vol. 83, no. 1, pp. 16-29, 1998.

[18] R. B. Litterman, "A Bayesian procedure for forecasting with vector autoregressions," Department of Economics Working Paper, Massachusetts Institute of Technology, 1980.

[19] R. B. Litterman, "Forecasting with Bayesian vector autoregressions: five years of experience," Journal of Business and Economic Statistics, vol. 4, no. 1, pp. 25-38, 1986.

[20] T. Doan, R. B. Litterman, and C. A. Sims, "Forecasting and conditional projection using realistic prior distributions," Econometric Reviews, vol. 3, no. 1, pp. 1-100, 1984.

[21] C. A. Sims, "A nine-variable probabilistic macroeconomic forecasting model," in Business Cycles, Indicators, and Forecasting, J. H. Stock and M. W. Watson, Eds., University of Chicago Press, Chicago, Ill, USA, 1992.

[22] C. A. Sims and T. A. Zha, "Bayesian methods for dynamic multivariate models," International Economic Review, vol. 39, no. 4, pp. 949-968, 1998.

[23] R. J. Hyndman and Y. Khandakar, "Automatic time series forecasting: the forecast package for R," Journal of Statistical Software, vol. 27, no. 3, pp. 1-22, 2008. 


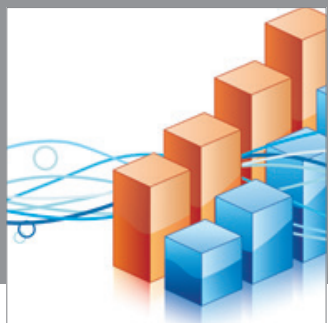

Advances in

Operations Research

mansans

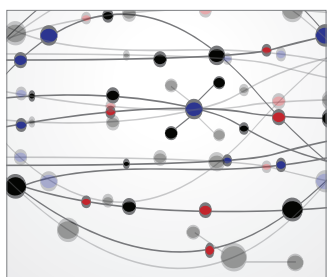

The Scientific World Journal
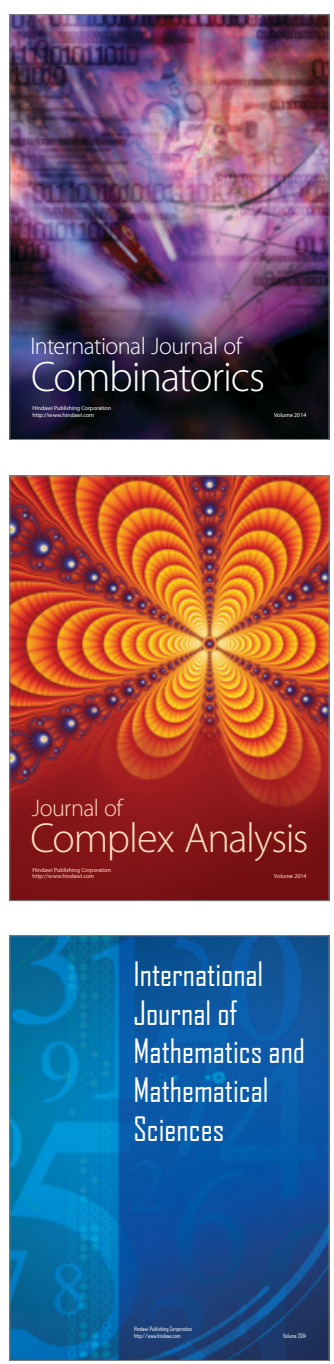
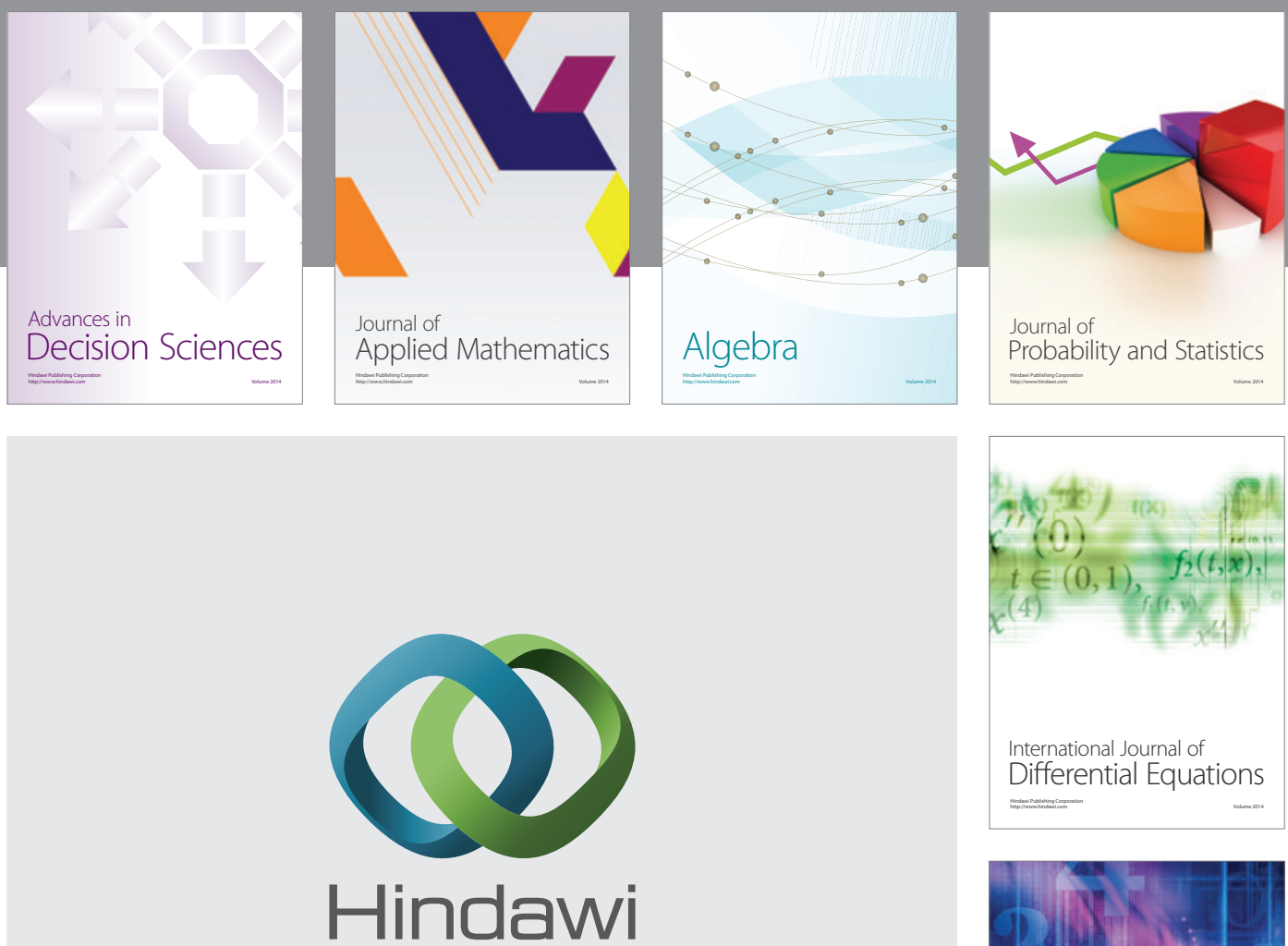

Submit your manuscripts at http://www.hindawi.com
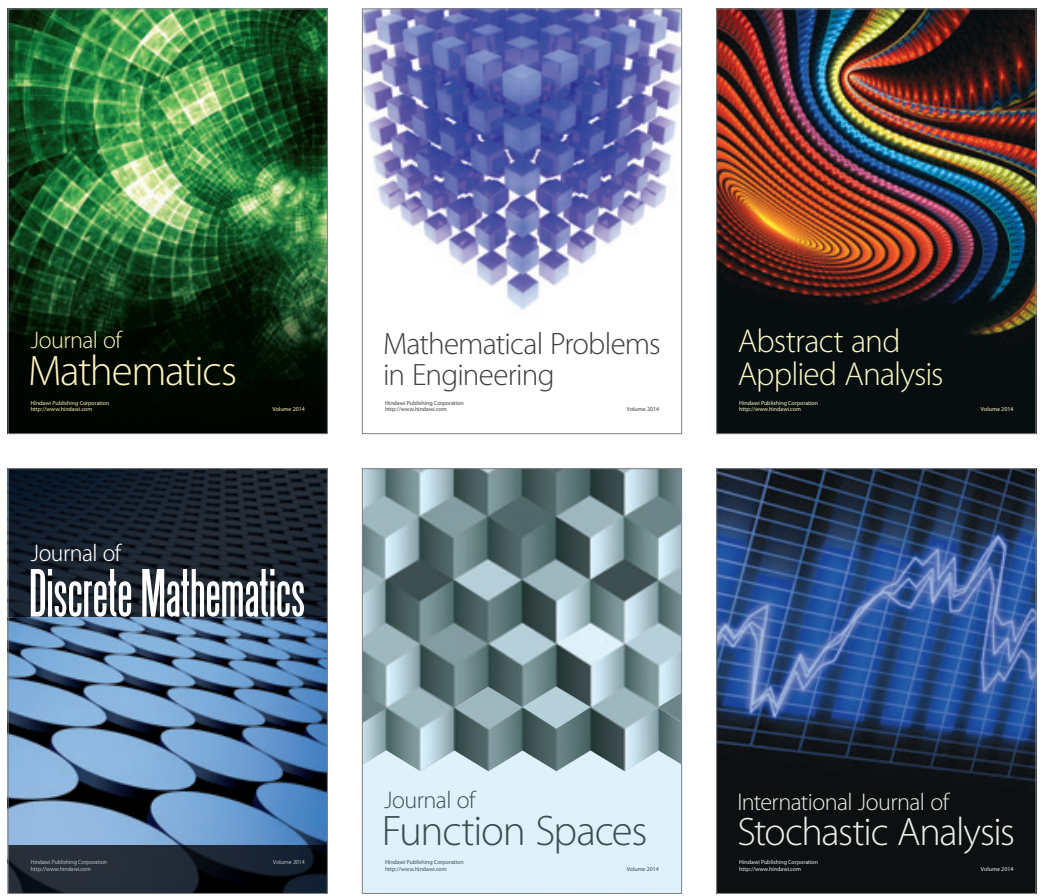

Journal of

Function Spaces

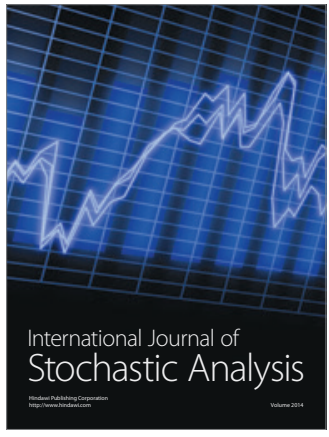

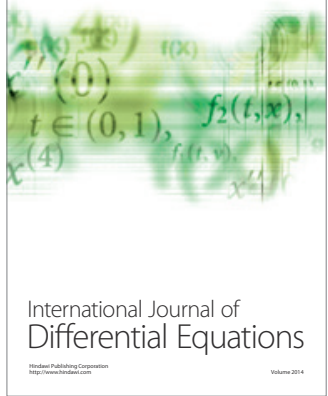
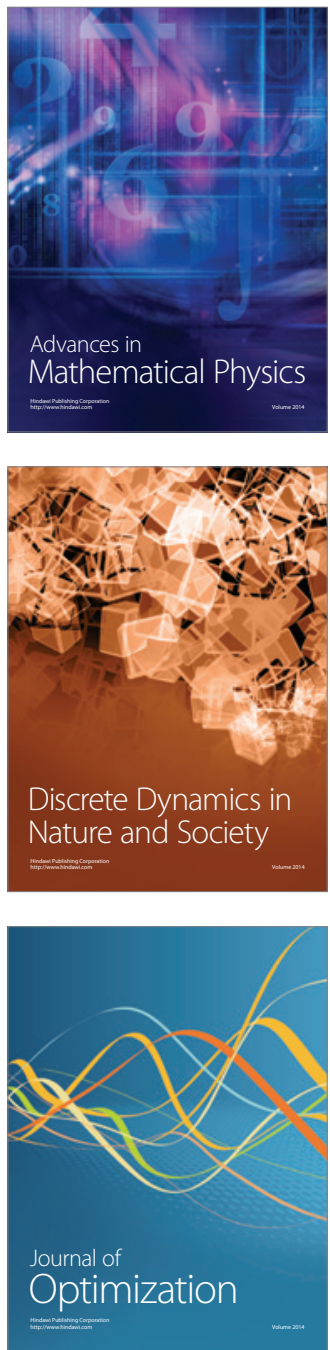